\title{
Urban transport planning for the North West University (Potchefstroom campus) and its environs: approach and core findings
}

\author{
C. B. Schoeman \& E. J. Cilliers \\ Department of Urban and Regional Planning, North West University, \\ Potchefstroom Campus, South Africa
}

\begin{abstract}
The North West University (NWU) is currently in a process of transformation due to the integration of higher education entities as a result of the democratization process that commenced in 1994. NWU is faced with various problems related to transport planning, parking provision, congestion and traffic flow. The actuality of this research is related to differences in trip making patterns of students, staff and visitors, as well as availability of public transport services and policies. This paper reports on research findings related to these inter relationships that resulted in ad hoc planning of facilities, and appropriate planning parameters which need to be developed and implemented in order to address the current reality and problems. The paper concludes with various transport planning solutions and alternatives selected through application of multi-criteria analysis. The transport plan includes optimal solutions for implementation that will enhance the planning and operation of road infrastructure supported by public transport services and measures as to address the local situation. Various universities in South Africa are also dealing with transport and spatial planning problems resulting from transformation based on integration of higher education institutions. This research is focussed on transportation and traffic implications related to university campuses. Approaches on how it can be accommodated within the institutional transformation scenario are discussed, and will thus be of benefit to all universities located in urban areas in South Africa.

Keywords: campus development, traffic generation, transformation, congestion, accessibility, future integration, multi-criteria analysis, integrated transport plan.
\end{abstract}




\section{Introduction and purpose of the paper}

Research in campus transport planning focuses on the establishment of planning parameters and methodologies which could improve local transport provision (Byam [1]). This statement is specifically applicable to the North West University (NWU) (Potchefstroom Campus) in South Africa. The NWU (hereafter refer to as the study area) is a vibrant campus that reflects a constant annual growth of $1.8 \%$ in terms of total student enrolment. The total number of students on campus in 2007 is 17 255. It is planned that undergraduate intake will remain constant as from 2008 as a system of capping of undergraduate intake will be applied. The intake or enrolment in 2007 consists of some $31.7 \%$ post-graduate students (2006) (NWU [2]). The projection in terms of the Institutional Plan of the NWU is that for 2010 some $37 \%$ and for 2015 some $40 \%$ of total student intake will consists of undergraduate students. Future growth will thus be based on post-graduate students with different needs in terms of accommodation and transport. The estimated current backlog in parking on campus is estimated at 1509 parking bays.

Staff and visitor numbers are increasing simultaneously and this leads towards various transport problems on campus, such as congestion due to increasing demand, slow traffic flow and growing backlogs in parking provision. Through extensive traffic and parking research supported by surveys and analysis of the infrastructure required to address the estimated transport related backlogs and future demand, it was found that the available infrastructure do not have sufficient carry capacity to effectively and efficiently serve the area from a transport planning perspective. Spatial and development planning solutions is core to the effective functioning of the transport networks to serve inter- and intra transport demand on campus. The purpose of this paper is to give an overview of the nature of the current transportation and traffic problems; to discuss the alternative solutions for the identified problems and to determine alternative solutions via the application of multi-criteria analysis. Due to the lack of an Integrated Transport Plan (ITP) some ad hoc interventions are formulated to address the short to medium term situation on a micro as well as macro transport scale. An ITP is needed to accommodate the current and future situation on the Potchefstroom Campus, and to address the spatial and transport implications within the greater area of influence.

\section{Methodology}

The demarcation of the study area is focussed on two entities, the NWU (Potchefstroom Campus), and the adjacent urban (Bult) area. Each of these spatial entities has unique transport problems and characteristics. Detailed transportation studies and surveys, within the demarcated area, were conducted to evaluate current transport realities and tendencies on and around campus. The status quo was analysed in terms of the current development and management policies. The research data was evaluated and the output led to a spatial and transport analysis of the current situation. The research output served as input in 
terms of alternative land use and transportation proposals. The aim was to compile a planning policy that can be implemented as an intervention strategy within the short term. At the same time provision should be made to include spatial and transport proposals strategies and proposals for the medium to long term in order to address the transportation problems in an integrated and holistic fashion.

\section{Determinants for sustainable transport development}

Sustainable transport development within the study area (including the NWU Campus and the Potchefstroom Local Municipality (LM)) is influenced by various impacts and determinants:

- The marketing and growth strategy of the NWU impact on future development and growth proposals, as it guides spatial development and future transport demand based on student intake.

- The development vision and objectives of the LM will impact on the provision of sustainable spatial and transport development within the study area.

\subsection{The North West University marketing and growth policy}

As indicated in the introduction to this paper the strategic objectives of the Potchefstroom Campus have a great influence on the future spatial and transport development in the study area. The revised marketing strategy of the university is focused on post-graduate students, where in the previous strategy was focussed on under-graduate students. In 2007 the student intake is estimated at 17255 students of which some 11507 fall within the category of under-graduate students. This implies a post-graduate intake of 5748 students [2]. An average $1.98 \%$ growth rate per annum (depending on the duration of post graduate studies) in post-graduate students is predicted during the next 3 tot 10 years, that will imply a figure of 6750 intake by 2010 and 7530 by 2015 intake of postgraduate students. This will impact on future development of university facilities and transportation networks, as different accommodation and transportation needs for post-graduate students will have to be planned for.

\subsection{Future vision for the local municipality}

Integrated Development Plans (IDP's) in South Africa are being prepared and implemented for every local spatial system (municipality) in terms of the provisions Section 26 of the Municipal Systems Act of 2000 [3]. The IDP's combines a strategic plan and elements of a meta-plan which links with a series of sector plans (water services development plans, transportation plans etc) and planning processes [4]. Transport planning in South Africa became a statutory planning activity with the enactment of the Urban Transportation Act (Act 78 of 1977) $[5,6]$. An important element in the alignment of the IDP and Integrated Transportation Plan (ITP) processes is the preparation of a spatial development framework (SDF) for local spatial systems (RSA [7]). The future development 
plan for Potchefstroom Local Municipality is described and illustrated in the revised Spatial Development Framework (SDF) of 2007. This framework identified the university and adjacent areas as a development node. According to the Residential Policy of Potchefstroom, the adjacent Bult area is demarcated for student accommodation [8]. The SDF includes no direct approaches towards the transportation problems in this area. The NWU will have to take initiative to develop this node, but the proposed planning and development of infrastructure and transportation networks within this node must be in accordance to the vision of the Local Municipality and the relevant IDP and SDF. This situation implies a situation of co-operative governance between the NWU and LM in the development of the area and addressing the transportation issues.

\section{Transportation research process}

Desk studies and transport surveys were conducted to evaluate current transport realities on campus and in the adjacent urban areas. Core elements were analyzed and evaluated to determine specific strengths and weaknesses. Status quo campus data consisted of census data sets, land uses, parking accessibility, pedestrian paths and projected growth. Status quo in the adjacent areas was determined by quantification of land uses, parking accessibility, business and office facilities, transport and road infrastructure, intersection analysis and the public transport services. Specific other quantitative as well as qualitative planning factors and elements in the Town Planning Scheme of Potchefstroom were identified as core aspects within the study area [9], as described in Table 1.

These above mentioned transport elements are subject to the transport demand as illustrated in Table 2, as well as the transport demand as illustrated in Table 3 .

Table 1: $\quad$ Status quo and current reality within the study area.

\begin{tabular}{|l|l|l|}
\hline Description & Current reality Campus & Current reality Adjacent area \\
\hline Spatial form & Compact, limited & Fragmented \\
\hline \multirow{3}{*}{ Parking } & Staff: increasing & Residential: SDF prescribes \\
\cline { 2 - 3 } & Students: dualistic. & Shops: insufficient loading zones \\
\cline { 2 - 3 } & Visitors: insufficient & Customers: insufficient \\
\hline Pedestrians & Accessible, walking distance & No policy for adjacent areas. \\
\hline \multirow{2}{*}{ Bicycles } & Lanes: informal & Lanes: not provided \\
\cline { 2 - 3 } & Facilities: limited provision & Facilities: none \\
\hline Public transport & None & Taxi facilities in urban areas. \\
\hline Accessibility & Good & Limited road network via the N12. \\
\hline Road network & Good & Ineffective two way road network \\
\hline Accommodation & Hostel capacity reached limit & Ad hoc extension of accommodation \\
\hline
\end{tabular}

\section{Formulation of objectives and development guidelines}

Based on the status quo and current reality assessment, specific transportation related objectives were compiled. These were based on inter- and intra movement network considerations from a campus wide and urban integration 
perspective. The proposed transport solution needs to address these problems and guide spatial development towards realizing the objectives, as formulated and described in Table 4.

Table 2: $\quad$ Estimated traffic demand within the study area.

\begin{tabular}{|l|l|l|l|l|l|l|}
\hline Traffic Demand & $\mathbf{2 0 0 7}$ & $\mathbf{\%}$ & $\mathbf{2 0 1 0}$ & $\mathbf{\%}$ & $\mathbf{2 0 1 5}$ & $\mathbf{\%}$ \\
\hline Total number of staff & 4100 & 100 & 4200 & 100 & 4400 & 100 \\
\hline Total number of students & 17255 & 100 & 18257 & 100 & 19037 & 100 \\
\hline Undergraduate students & 11507 & 66.7 & 11507 & 63 & 11507 & 60 \\
\hline Post-graduate students & 5748 & 33.3 & 6750 & 37 & 7530 & 40 \\
\hline Total private vehicle ownership & 6406 & 30 & 7410 & 33 & 8437 & 36 \\
\hline Estimated demand of parking bays & 6100 & 100 & 7100 & 100 & 8100 & 100 \\
\hline
\end{tabular}

Table 3: $\quad$ Estimated traffic supply within the study area.

\begin{tabular}{|l|l|l|l|l|l|l|}
\hline Traffic Supply & $\mathbf{2 0 0 7}$ & $\mathbf{\%}$ & $\mathbf{2 0 1 0}$ & $\mathbf{\%}$ & $\mathbf{2 0 1 5}$ & $\mathbf{\%}$ \\
\hline Parking bays provided staff & 500 & 10.1 & 550 & 9.2 & 600 & 8.5 \\
\hline Parking bays provided students & 4100 & 89.8 & 6000 & 90.8 & 7000 & 91.5 \\
\hline Parking bays provided West campus & 968 & 21.1 & 1468 & 24.4 & 2086 & 29.6 \\
\hline Parking bays provided East campus & 3624 & 79.1 & 5424 & 73.5 & 5824 & 68.5 \\
\hline Parking bays provided conservatorium & 103 & 2.2 & 123 & 2.0 & 123 & 1.7 \\
\hline Estimated supply of parking bays & 4580 & 100 & 7015 & 100 & 8033 & 100 \\
\hline
\end{tabular}

Table 4: $\quad$ Formulation of transport objectives and development guidelines.

\begin{tabular}{|l|l|l|}
\hline Description & Goal on Campus & Goal on Adjacent urban area \\
\hline Spatial form & Integration, hostel development & Grid layout revised, integration \\
\hline Accessibility & Optimized integration, linkages & Develop connection roads with N12 \\
\hline Road network & Link with facilities & Replace with one way road network. \\
\hline Public transport & Provision campus shuttle service & Extend facilities for busses \& taxi's \\
\hline Public facilities & Support movement network & Support movement network \\
\hline Parking & Spatial allocation re-evaluated & Develop garage \\
\hline Pedestrians & Integrate with public transport & Develop pedestrian lanes \\
\hline Bicycle & Link Campus and adjacent area & Provide bicycle lanes, facilities, safety \\
\hline Accommodation & Accommodate demand & Development of student village \\
\hline
\end{tabular}

Table 5 illustrates the proposed transport solutions in terms of the goals formulated above. The relevant planning solutions are formulated against the current reality, goals, and objectives to serve the roles of the NWU, LM as well as the private sector. The type of solution, the responsible authority to guide successful implementation and the specific projected implementation timeframe is included.

\section{Implementation of transport and traffic solutions}

Research, desk studies and transport surveys were conducted to formulate various solutions to the current reality and transport problems. Via a 


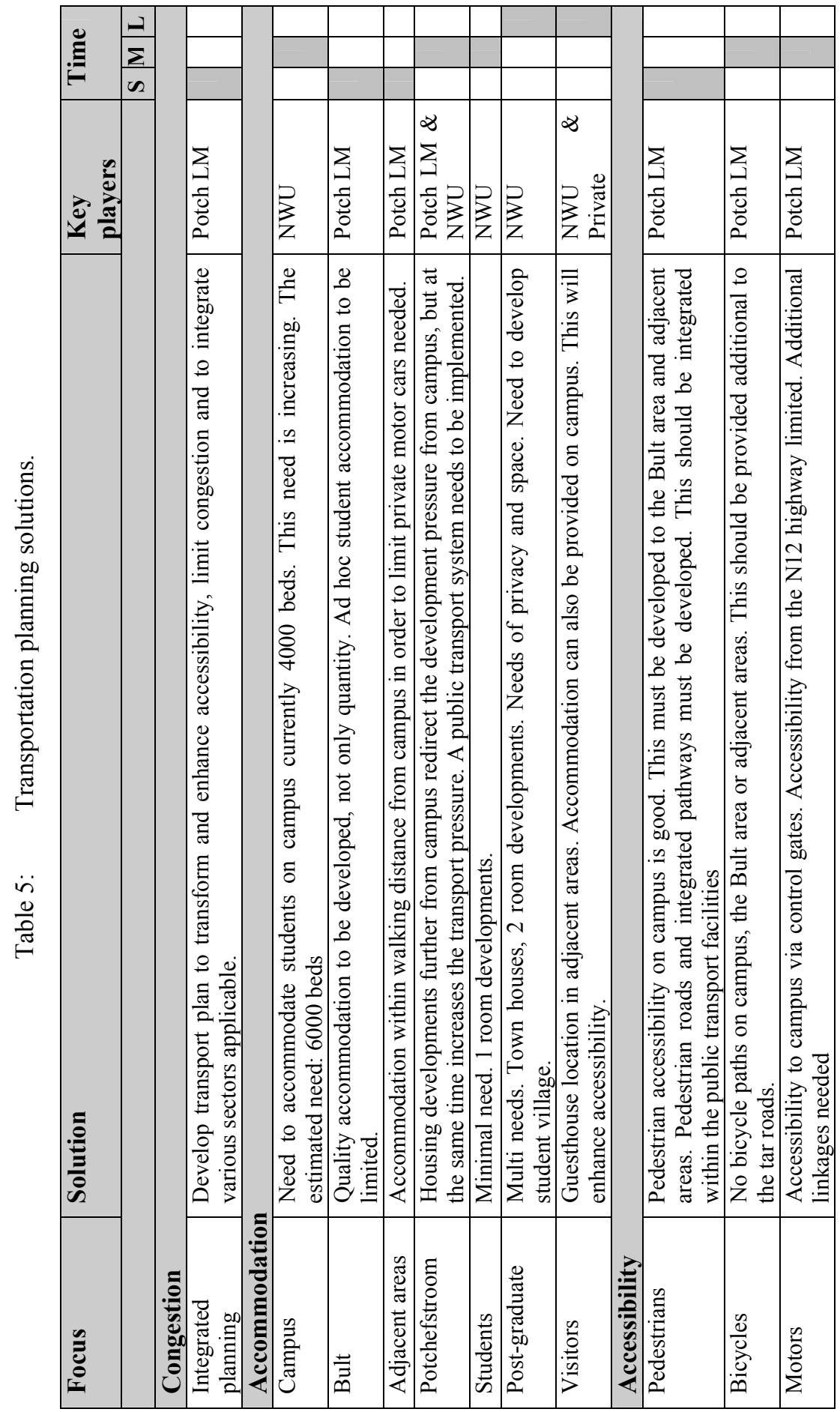




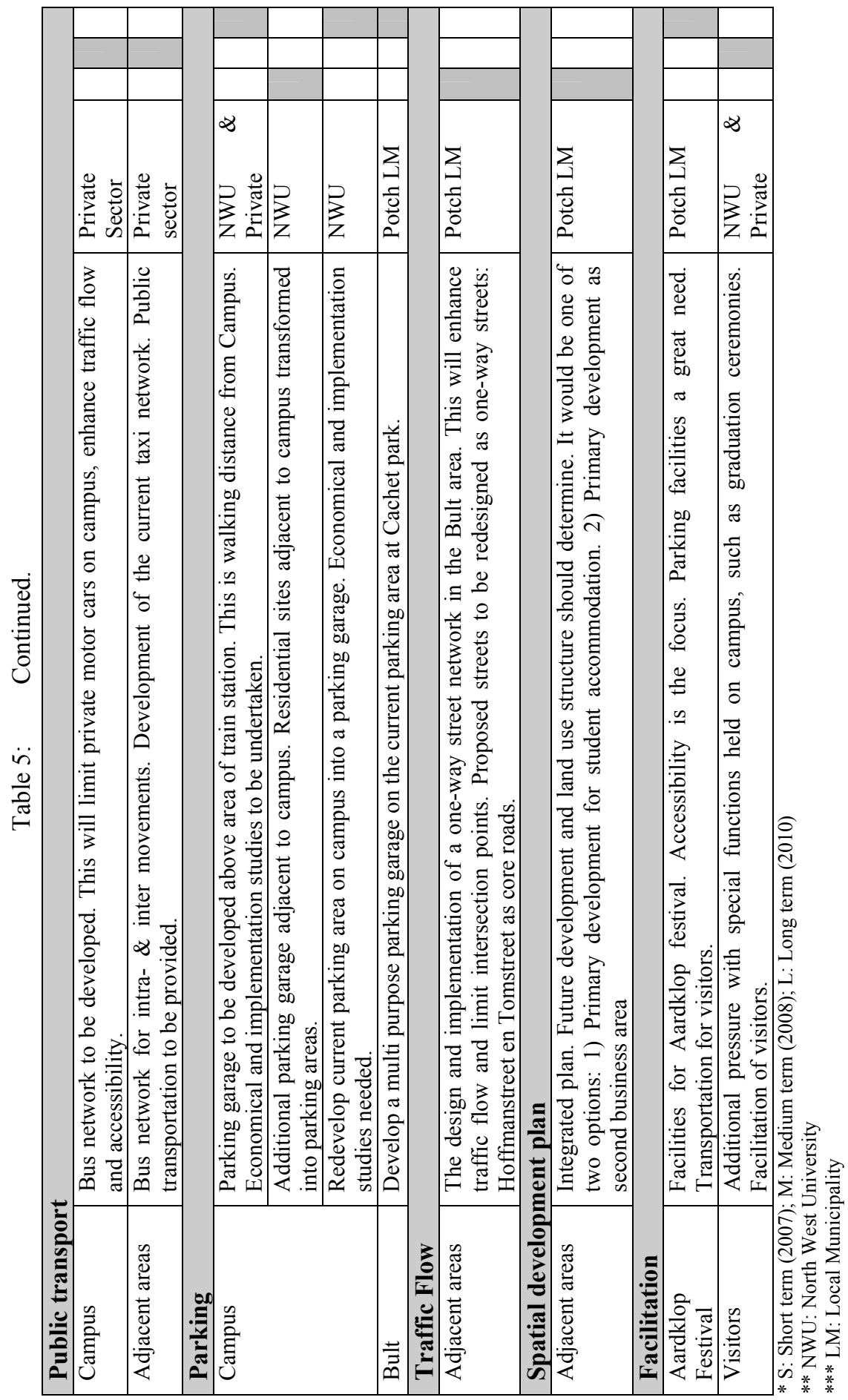

WIT Transactions on The Built Environment, Vol 96, (C) 2007 WIT Press www.witpress.com, ISSN 1743-3509 (on-line) 
multi-criteria analysis these proposed solutions were evaluated against each another to determine the most effective and efficient solution for the mentioned transport and parking problems on and in the vicinity of the study area.

Potential solutions included the following project alternatives:

- Development of a parking garage on campus

- Development of a parking garage at Cachet shopping mall

- Development of parking areas on collective residential areas

- Development of parking areas above the railway space on campus

- Implementation of a public transport service (campus shuttle)

- Development of parking on selective residential stands

Each of these project alternatives (solutions) was evaluated based on the following factors (as illustrated in Table 6):

- Initial costs: short term objective (feasibility studies, obtaining sites etc)

- Construction costs: short term objective (development, building)

- Management costs: long term objective

- Operational costs: long term objective

- Distance from campus in meter: applicable to sustainability of the project

- Implementation time in months: short, medium, long term realization

Table 4 illustrates these various projects (solutions) for the transportation and parking problems in terms of implementation time and costs and distance.

Table 6: $\quad$ Costs of parking solutions in South African Rand (R) and Euro (€).

\begin{tabular}{|c|c|c|c|c|c|c|}
\hline Factor & 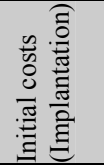 & 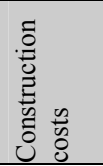 & 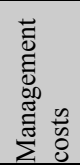 & 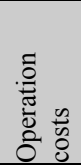 & 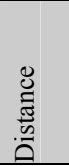 & 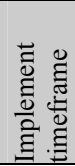 \\
\hline Parking garage campus & $\begin{array}{l}25000 \\
(2631)\end{array}$ & $\begin{array}{l}50000 \\
(5263)\end{array}$ & $\begin{array}{l}3000 \\
(315)\end{array}$ & $\begin{array}{l}2500 \\
(263)\end{array}$ & 100 & 14 \\
\hline Parking garage Cachet & $\begin{array}{l}35000 \\
(3684)\end{array}$ & $\begin{array}{l}1000 \\
(105)\end{array}$ & $\begin{array}{c}1500 \\
(157)\end{array}$ & $\begin{array}{l}1000 \\
(105)\end{array}$ & 300 & 8 \\
\hline Collective areas & $\begin{array}{l}150000 \\
(15789)\end{array}$ & $\begin{array}{l}55000 \\
(5789)\end{array}$ & $\begin{array}{l}5000 \\
(526)\end{array}$ & $\begin{array}{l}3500 \\
(368)\end{array}$ & 1500 & 12 \\
\hline Parking above railway & $\begin{array}{l}65000 \\
(6842)\end{array}$ & $\begin{array}{l}100000 \\
(10526)\end{array}$ & $\begin{array}{l}5000 \\
(526)\end{array}$ & $\begin{array}{l}3500 \\
(368)\end{array}$ & 200 & 18 \\
\hline Public transport service & $\begin{array}{l}250000 \\
(26315)\end{array}$ & $\begin{array}{l}150000 \\
(15789)\end{array}$ & $\begin{array}{l}6000 \\
(631)\end{array}$ & $\begin{array}{l}4500 \\
(473)\end{array}$ & 1500 & 12 \\
\hline Residential Stands & $\begin{array}{l}100000 \\
(10526)\end{array}$ & $\begin{array}{l}35000 \\
(3684)\end{array}$ & $\begin{array}{l}1500 \\
(157)\end{array}$ & $\begin{array}{l}1000 \\
(105)\end{array}$ & 400 & 10 \\
\hline
\end{tabular}

Standardizing this data leads to a better distribution of the data. Each component was given a certain weight in order to determine the total impact of the proposed solution. The formula delivered the weight as follows: Initial costs (0.118), construction costs $(0.161)$, management costs $(0.199)$, operational costs $(0.199)$, distance $(0.161)$ and implementation time $(0.161)$. These weights were 
substituted in each of the projects (solutions) and compared to determine the best solution. Figure 1 illustrates the result of the comparison of projects (solutions). According to the multi-criteria analysis the best option would be to develop a parking area at Cachet. The second best option is to development adjacent residential stands into parking areas. The development of a public transport system will be to the least benefit in this case.

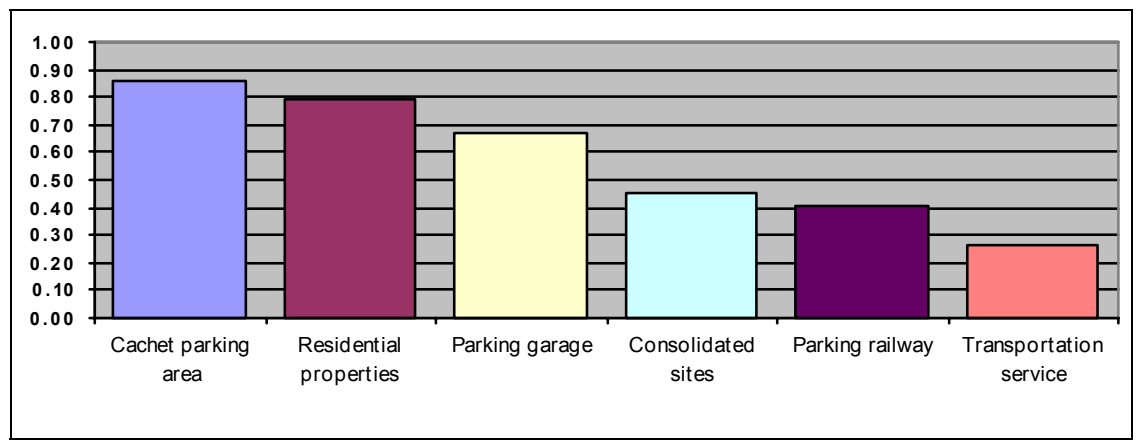

Figure 1: $\quad$ Comparison of projects (solutions).

Figure 2 illustrates the sum of the different individual weights (determinants) as described in Table 4, which adds up to the success of the projects (solutions).

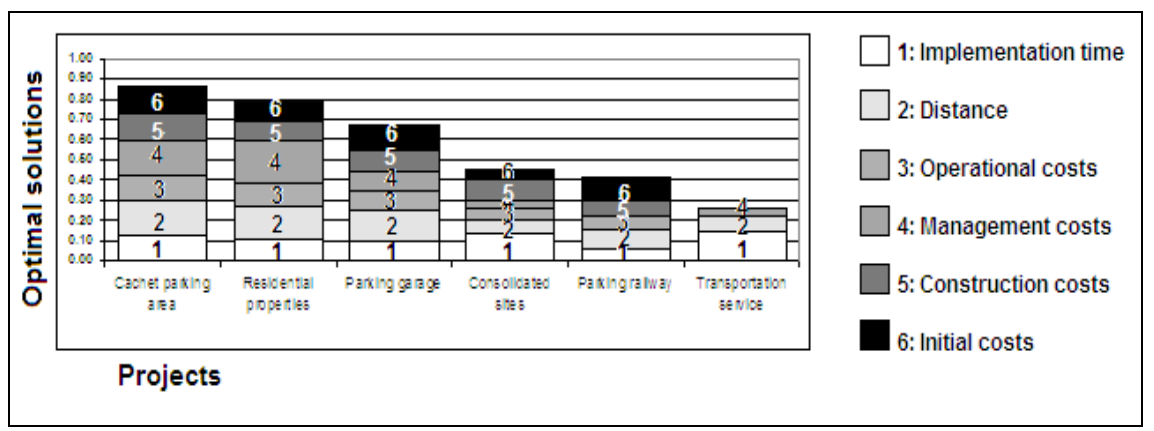

Figure 2: Distribution of the costs of each solution.

The multi-criteria analysis illustrates (Figure 3 ) the optimum solution. This is an illustration of the data of Figure 2. The optimal solution would be the development of a parking area at Cachet Park. The second best option would be to develop on adjacent residential stands. The third option would be to develop a parking garage on campus. The development of a public transport system will be to the least advantage according to the multi-criteria analysis. 
110 Urban Transport XIII: Urban Transport and the Environment in the 21st Century

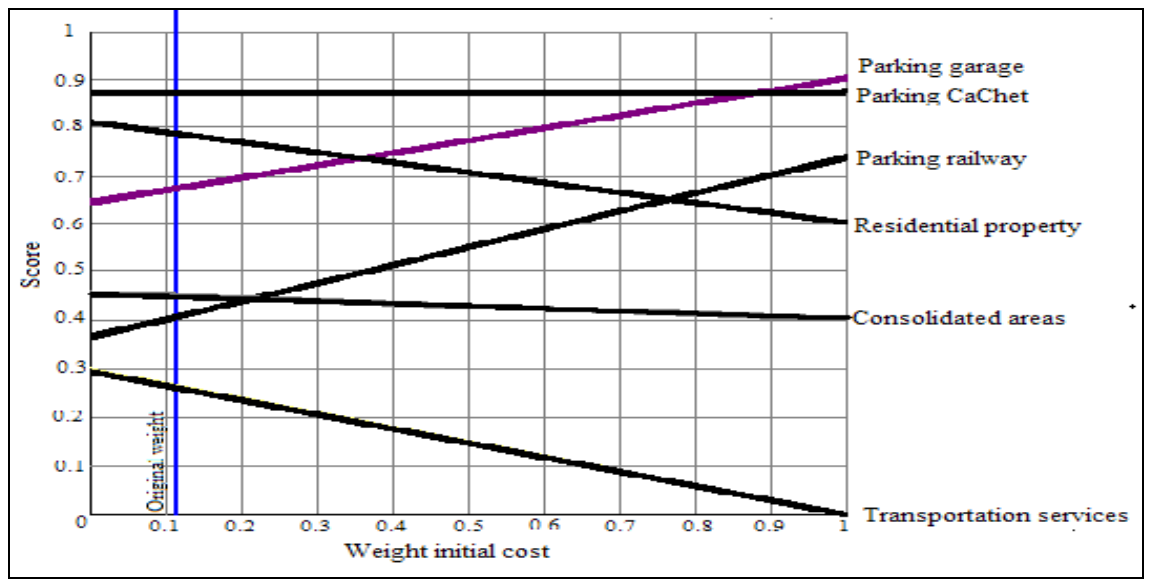

Figure 3: Multi-criteria analysis of the proposed projects (solutions).

\section{Optimum transport solution alternatives}

The three optimum transport alternatives (as described in section 6) were further compared in terms of implementation time and costs, as illustrated in Table 7.

Table 7: $\quad$ Matrix of proposed alternatives.

\begin{tabular}{|c|c|c|c|}
\hline Solution & 1: Parking Cachet & 2: Residential Stand & 3: Garage campus \\
\hline Development & Public space & 10 adjacent sites & Building \\
\hline Current parking & 289 current spaces. & 0 & 0 \\
\hline Parking capacity & 500 & 3000 & 2000 minimum \\
\hline $\begin{array}{l}\text { Cost per parking } \\
\text { space } \mathrm{m}^{2}\end{array}$ & $\begin{array}{l}\mathrm{R} 200 / \mathrm{m}^{2} \\
(21 €)\end{array}$ & $\begin{array}{l}\mathrm{R} 200 / \mathrm{m}^{2} \\
(21 €)\end{array}$ & $\begin{array}{l}\mathrm{R} 1700 / \mathrm{m}^{2} \\
(178 €)\end{array}$ \\
\hline $\begin{array}{lcc}\text { Total cost } & \text { per } \\
\text { parking/space } & \end{array}$ & $\begin{array}{l}\text { R 3000 } \\
(315 €)\end{array}$ & $\begin{array}{l}\text { R } 3000 \\
(315 €)\end{array}$ & $\begin{array}{l}\text { R } 38000 \\
(4000 €)\end{array}$ \\
\hline Infrastructure cost & 0 & $\begin{array}{l}\mathrm{R} 10000000 \\
(1052631 €)\end{array}$ & 0 \\
\hline Construction cost & $\begin{array}{l}\text { R1500000 } \\
(157894 €)\end{array}$ & $\begin{array}{l}\text { R600 000 } \\
(63157 €)\end{array}$ & $\begin{array}{l}\text { R76000000 } \\
(8000000 €)\end{array}$ \\
\hline Total project costs & $\begin{array}{l}\text { R1500000 } \\
(157894 €)\end{array}$ & $\begin{array}{l}\text { R10600000 } \\
(1115789 €)\end{array}$ & $\begin{array}{l}\text { R76000000 } \\
(8000000 €)\end{array}$ \\
\hline Construction time & Short term & Medium term & Long term \\
\hline $\begin{array}{l}\text { Negative impact/ } \\
\text { challenges }\end{array}$ & $\begin{array}{l}\text { Limited spaces, } \\
\text { Public use }\end{array}$ & $\begin{array}{l}\text { - Finding } 10 \text { sites } \\
\text { - Not adjacent }\end{array}$ & $\begin{array}{l}\text { - Long process } \\
\text { - Expensive }\end{array}$ \\
\hline $\begin{array}{l}\text { Positive impact/ } \\
\text { challenges }\end{array}$ & $\begin{array}{l}\text { - } \quad \text { Cheapest } \\
\text { - } \quad \text { Short term }\end{array}$ & $\begin{array}{l}\text { - Additional areas } \\
\text { - Private use }\end{array}$ & $\begin{array}{l}\text { - Capital expenses } \\
\text { - Private use }\end{array}$ \\
\hline
\end{tabular}




\section{Conclusions}

- The above mentioned solutions for the transportation and traffic problems at the NWU are project specific. These projects are proposed for development over the short, medium and long term implementation timeframe.

- The success of these solutions will be subject to the integration of the related spheres of government, effective management policies, and integration within the SDF and IDP for Potchefstroom Local Municipality.

- These contexts as described in this paper represent the current reality and situation within the Potchefstroom Local Municipality, and the proposed solutions will serve as a point of departure for the development and compilation of an Integrated Transport Plan for the LM. The non-existence of an ITP represents an important shortcoming within the current IDP process.

- The lack of capacity within municipalities for service delivery has been identified in the White Paper on Municipal Service Partnerships of 2000 [10]. The White Paper on Transportation (Moving South Africa) has identified the public transport problem in South Africa, currently present in Potchefstroom and enhancing the need for the integrated transport plan. As far as alignment from a management perspective between ITP's and IDP's is concerned, the National Land Transport Transition Act [11] makes provision for the establishment of transport authorities (TA's) for specific transport areas (TRA's) (Part 5). This provision implies that there will be within local spatial systems more than one authority dealing with transport and development planning matters respectively making cooperative governance critical, according to the Town Planning Scheme of Potchefstroom [9].

- The guiding impact of the general principles for transport planning and its relationship with land development (Section 18) should be noted. Circumstances and planning needs are not homogeneous between provincial spatial systems and between local spatial systems 12]. The application of blueprint planning in IDP and ITP preparation defeat the objective of proper alignment. The lack of proper alignment between land use (spatial development) and transport is seen evident on provincial level. [13].

- Due to the integrated nature of land use and transport in urban development, Integrated Transport Plans (ITP's) as a sector input informs the preparation of Integrated Development Plans (IDP's) and visa versa. [9]. The nature of this alignment is important if Potchefstroom Local Municipality is to succeed in integrating its present divided urban structure as to realise the objectives of sustainable development.

- Potchefstroom Local Municipality has an IDP but it is not supported by sectoral plans. Thus, there is an urgent need to develop and compile an integrated transport plan. This is enhanced by the fact that Potchefstroom is not a metropolitan area, which has further implications for this region. There is no supporting infrastructure and public transportation services [8], as Gauteng Province have with the Gautrain or bus network. Residents are dependent on private vehicles and therefore the focus for development is on 
parking areas and facilities [13]. Transportation needs to be an integral part of the IDP and SDF of Potchefstroom Local Municipality.

- To ensure the successful implementation of the Integrated Transport Plan, mechanisms has to be developed to guide transportation and development, and partnerships has to be established between NWU, LM and the private sector to manage and implement these plans.

\section{References}

[1] Byam, E. Manager of Transit Services, University of Massachusetts, Amherst. [Web:] http://www.ntu.edu.sg/cts/rand.html

[2] North West University. Draft Institutional Plan: 2006-2008 and beyond. North West University. Potchefstroom. 2005.

[3] Republic of South Africa: Local Government: Municipal Systems Act (Act 32 of 2000). Government Printer, Pretoria, 2000.

[4] Republic of South Africa: Department of Provincial and Local Government, Towards Policy on Integrated Development Planning, Pretoria, 1998. Report prepared by Oranje, M.C., Harrison, P., \& Smith, G.

[5] Republic of South Africa: Urban Transportation Act (Act 78 of 1977): Government Printer, Pretoria. 1977

[6] Republic of South Africa: Report of the Committee of inquiry into Urban Transport Facilities in the Republic. Government Printer, Pretoria, 1974

[7] Republic of South Africa: Department of Provincial and Local Government, IDP Guide Packs. Guidelines for Integrated Development Planning, Formeset Printers Cape (Pty) Ltd. Cape Town for the Government Printers, 2001.

[8] Potchefstroom Municipality. Residential Policy for Bult and Dassierand Area Situated in Potchefstroom. Final Draft. November. 60p. Potchefstroom. 2005

[9] Potchefstroom Municipality. Potchefstroom Town Planning Scheme. 1980

[10] Republic of South Africa: White Paper on Municipal Service Partnerships. Government Printer, Pretoria, 2000.

[11] Republic of South Africa: National Land Transport Transition Act (Act 22 of 2000). Government Printer, Pretoria, 2000.

[12] Potchefstroom Municipality. Rural Policy Potchefstroom. November. 55p. Potchefstroom. 2006

[13] Potchefstroom Municipality. Urban Edge Policy November. 49p. Potchefstroom. 2006.

[14] North West University. Transportation study for the Potchefstroom Campus. Potchefstroom. November 2006.

[15] Map-info Professional 7.8 SCR. (2005). Multi-criteria analysis software. [http://reference.mapinfo.com/software/mapinfo_pro/english/Notes.pdf]. Potchefstrooom Campus 2007. 